\title{
The Use of Computer Applications in Public Audit (External)
}

\author{
Ioana LAZARESCU ${ }^{\star}$
}

\begin{tabular}{l}
\hline \multicolumn{1}{c}{ A R T I C L E I N F O } \\
\hline Article history: \\
Accepted December 2019 \\
Available online December 2019 \\
\hline JEL Classification \\
M40, M42 \\
Keywords: \\
Public funds, External public audit, \\
Romanian Court of Accounts, \\
CaseWare IDEA, Database
\end{tabular}

\begin{abstract}
A B S T R A C T
The public audit is a mechanism of control that ensures that the public funds are allocated and used in accordance with the applicable legal framework. The Romanian Court of Accounts exercises the external public audit of public funds through the following types of actions: financial audit, performance audit and compliance audit. An efficient audit technique is represented by the use of the CaseWare IDEA (Integrated Data Extraction and Analysis) computer application, which offers extraction, totalization, sampling and editing functions to identify errors, problems, frauds and trends. The external public auditors of the Chambers of Accounts are trained and use, in part, the CaseWare IDEA computer application, obtaining significant results in terms of working time efficiency. It is proposed to further disseminate the findings made with the CaseWare IDEA computer application to external public auditors who do not use it and to increase the degree of training in using this software product.
\end{abstract}

(C) 2019 EAI. All rights reserved.

\section{Introduction}

The public audit function is an integral part of government financial management, as well as a tool for increasing the performance of the government sector. Traditionally, public audit is a mechanism by which the executive and the legislature ensure that funds are received and consumed in accordance with how they are allocated, respecting the normative acts. The audit function has evolved in many countries, developing a perspective on the economic and social implications of public economic operations - often called "value for money" or performance audit.

In Romania, public external audit is exercised at the level of the Romanian Court of Accounts, the authority of the central public administration established under the provisions of Art. 140 of the Romanian Constitution and Law no. 94/1992 on the organization and functioning of the Court of Accounts.

The mission of the Romanian Court of Accounts is to support the promotion of responsibility, fairness and best practices in the efficient management of public resources, to strengthen financial management in Romania.

The audit / control activity performed by the Romanian Court of Accounts has the following objectives:

- the correct and effective use of the financial resources of the state and the public sector,

- the assessment of the implementation of the approved budget,

- the consolidation of good financial management,

- the proper execution of administrative activities, and

- informing public authorities and the general public through the preparation and delivery of objective reports.

The Romanian Court of Accounts carries out its own work and performs three types of audit: financial audit, performance audit and compliance audit (thematic control) based on its own audit standards developed in the light of the International Organization of Supreme Audit Institutions (INTOSAI), the International Federation of Accountants (IFAC), the European Guidelines for the Implementation of INTOSAI Auditing Standards, and best audit practices.

\section{Audit Procedures and Techniques - CaseWare IDEA computer application}

To obtain an audit test - any information used by auditors to determine whether data subject to audit are presented in accordance with predetermined criteria - to provide the findings, formulate conclusions, recommendations and audit opinion, external public auditors should apply audit procedures and techniques. 
An important role in this is the IDEA audit computer application, which is the acronym of Integrated Data Extraction and Analysis, developed by Canadian company CaseWare International Inc.

IDEA is a PC tool for database analysis, used by auditors, accountants, investigators, and IT staff. IDEA analyzes in multiple ways using extraction, totalizing, sampling, and editing to identify errors, problems, frauds and trends.

IDEA can be used to:

- identifying unusual exceptions or registrations;

- data analysis;

- making calculations;

- comparing and correlating files;

- testing discontinuities for multiple sequences and records;

- sampling.

This IDEA software is useful in delivering consistent, high performance auditing, providing a structured framework for conducting well-organized and effective audits that fulfill or sometimes exceed professional standards.

At present, the public external auditors of the Romanian Court of Accounts have available IDEA version 9.2. (2014), which simplifies data import and analysis, and provides results useful to auditors.

\section{The use of the IDEA application}

\subsection{Import of data and organization of work}

This audit software provides the auditors with the easiest and quickest way to import an infinite amount of records from any source, including spreadsheets and database software, from accounting files and archives, even if they are and older applications as well as printed files such as PDFs, plain text (.txt extension files), and print-to-file reports (.prn extension).

The simple and friendly interface of the software allows the auditors to work well organized in the File management window with the option of creating subfolders (subsequent folders), copying / moving databases, and opening, rename, add or merge various databases data. In the audit work, as in any other activity, when you are well organized and managing the information correctly, you are less distracted by the attention, and thus, you have longer time, so that, you can focus and achieve your specific goals and tasks.

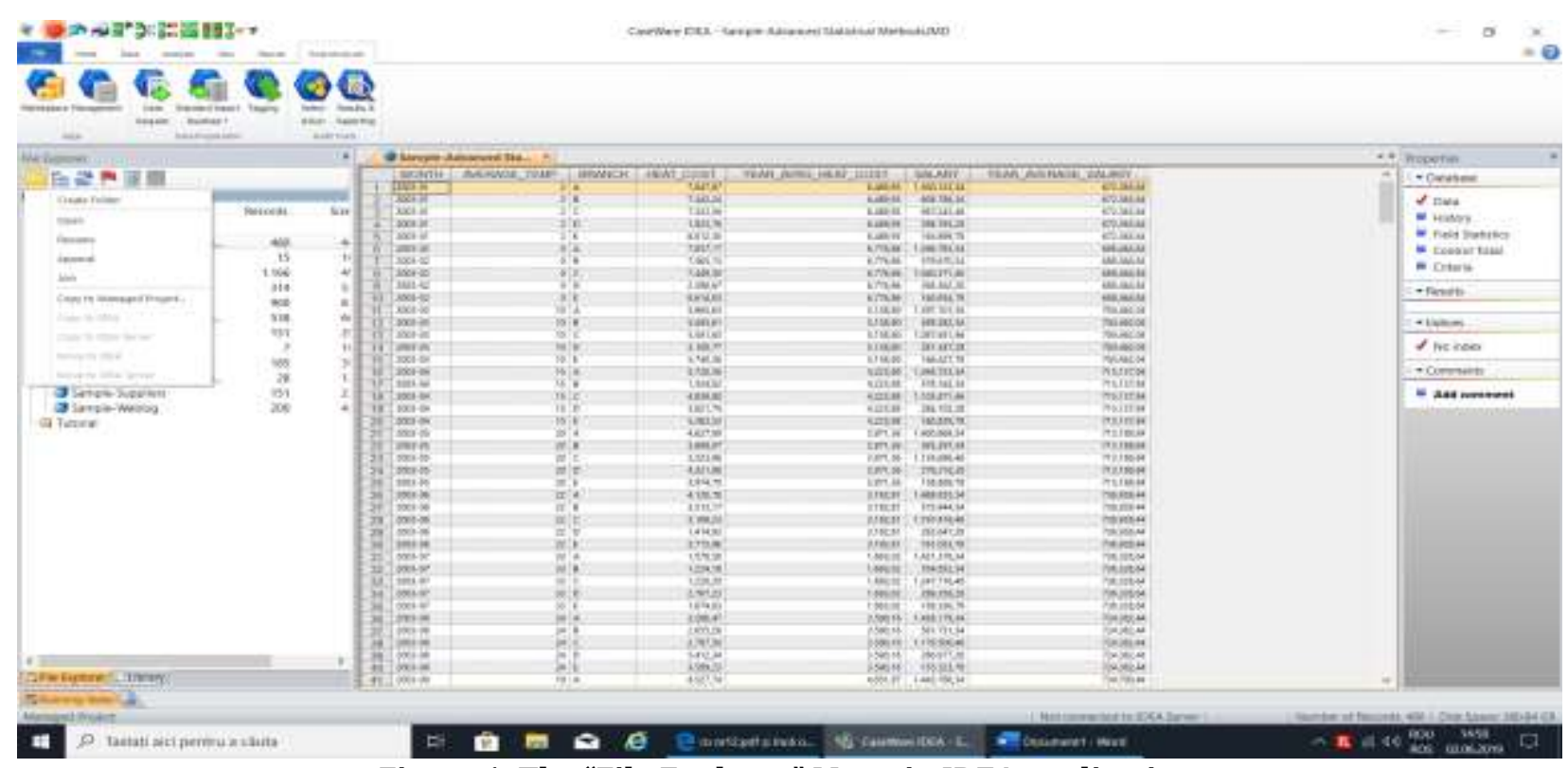

Figure 1. The "File Explorer" Menu in IDEA application

Source: Extract from CaseWare IDEA computer application

Longer lost time with searching for data and information means, in fact, less time used to trace relationships, patterns and abnormalities in the activity of entities. This software provides easy access to imported data, providing users with all sorts of custom features, import definitions, and source file information. The auditors can easily navigate through imported files to view their properties, the size and date of the latest changes.

According to the file import wizard in the IDEA application, data can be loaded from the following file types:

\# AS400 (Application System 400), which represent a series of computers produced and distributed by IBM since 1988 and designed for small or medium sized businesses; 
dBASE, which was one of the first database management systems for personal computers;

Microsoft Access, which is part of the office application suite Microsoft Office;

\# Microsoft Excel, idem;

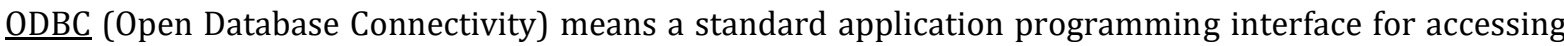
database management systems;

* Print Report and Adobe PDF refer to printer report files, exported by various programs, and that contain instructions for a printer about what to print, what type of paper to use, what paper size, and more;

* SAP SmartExporter, which is the solution for extracting and analyzing SAP villages (a German software company and organization), an application designed to export easily and automatically prepare SPA data for further analysis;

* SAP/AIS (Audit Information System) is an original SAP tool designed to assist in auditing technical and business controls in an SAP system;

* Text, is a file that is structured as a sequence of electronic text lines;

* XML (Extensible Markup Language) is a language created for the purpose of data transfer between applications on the Internet.

The "Import Assistant" menu in the IDEA application is shown in the image below:

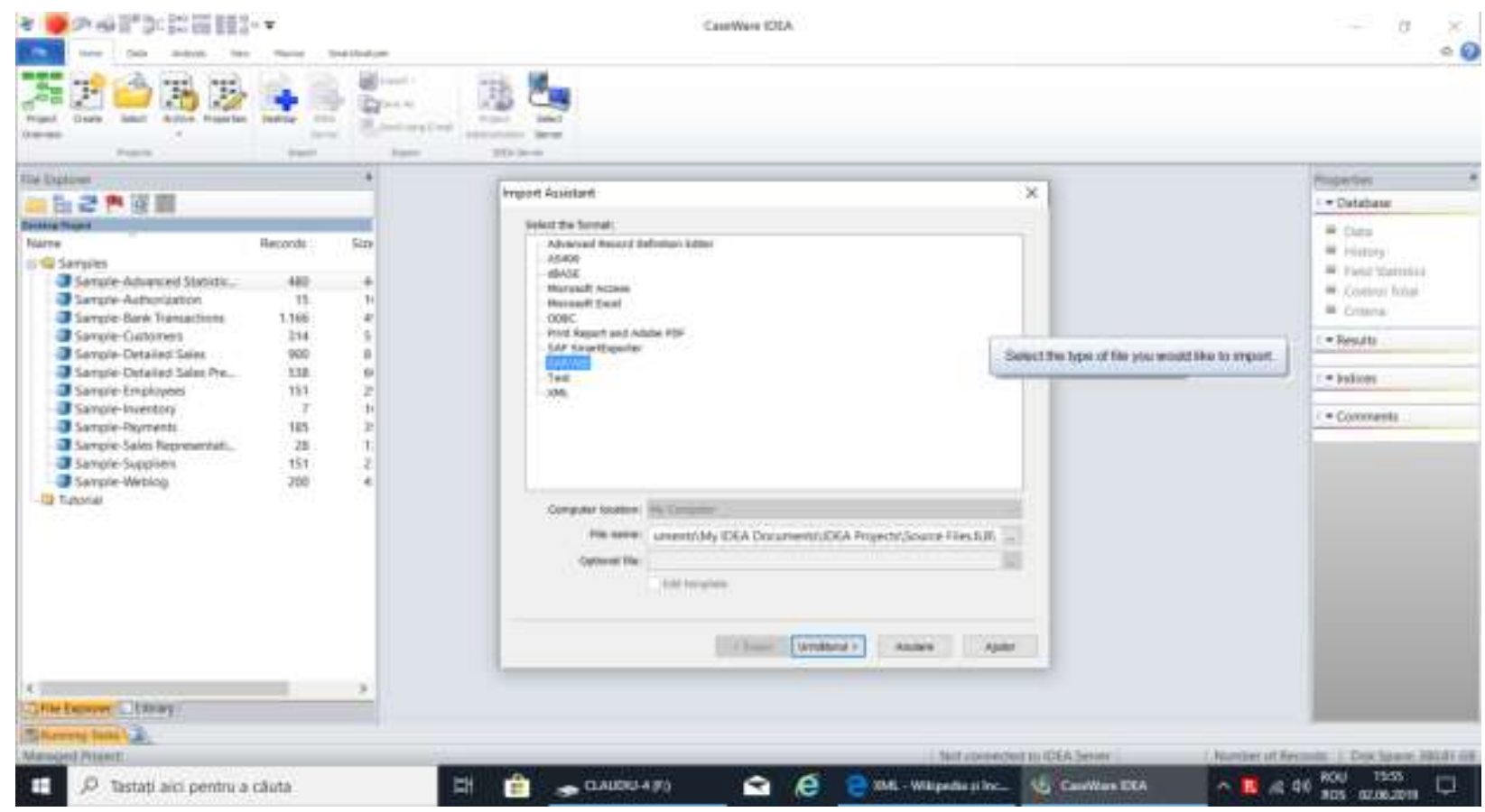

Figure 2. The "Import Assistant" menu in the IDEA application

Source: Extract from CaseWare IDEA application

\subsection{Analysis and standardization}

With IDEA, the auditor can run complex database queries and perform some more sophisticated calculations, while maintaining the integrity of all data.

Using the IDEA software, the auditors have the ability to import multiple data sets and view them as if they are a whole, allowing the auditors to see the whole picture. In this situation, the auditors are able to identify existing relationships, patterns and anomalies, but they also have the opportunity to explore data and information in depth. With this new version of the software, the auditors have the ability to extract directly from a database that shows columns of value information, the largest or smallest records. This is the Top Records feature in the Analsys window. With this function the auditors can extract the desired number of records that will form the audited operations samples. 


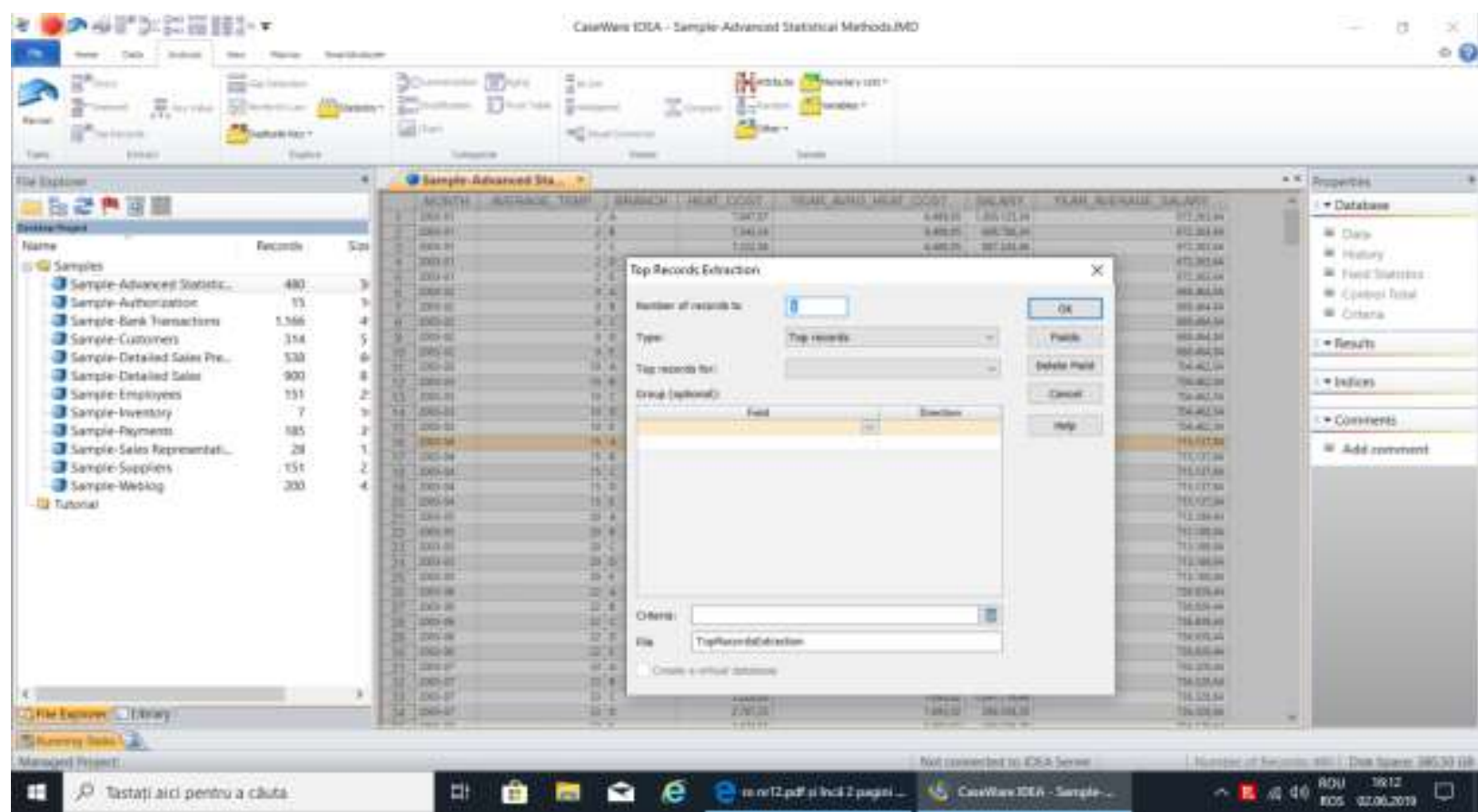

Figure 3. A function ("Top Records Extraction") used by the auditors to extract the desired number of records that will form the audited operations samples

Source: Extract from CaseWare IDEA application

The selection criteria offered by the application are, among other things: the number of records to be selected, the type of selection (the largest or smallest records), the field from which to select the records, other filtering conditions and the file name in which the save the selection results.

A profound analysis of information has the primary effect of minimizing the risks and maximizing the efficiency of the activity. When the auditor's work is primarily aimed at identifying and analyzing risks, the coverage of $100 \%$ data can make a difference. entities.

IDEA ensures full visibility and timely access to each transaction that affects the activity of verified

Another useful feature is Gap detection (Detecting discontinuity), which could be used, for example, when analyzing a series of invoices. Typical invoice numbering is a continuous sequence. To check for missing invoices, use the Gap Detection function.

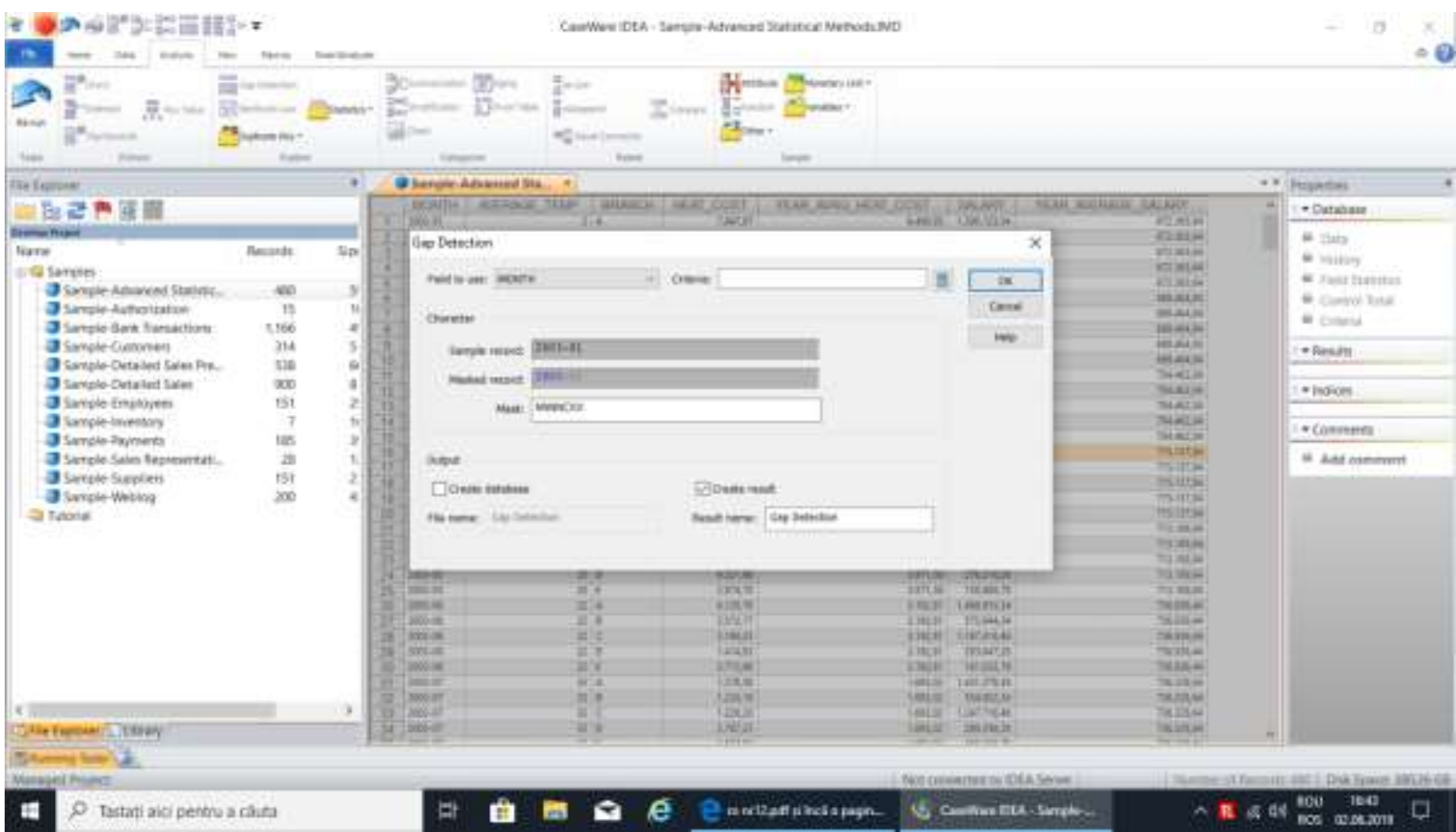

Figure 4. Selection Criteria: Selection field, selection criterion, type (model) record, resulting database name, used in the "Gap Detection" function

Source: Extract from CaseWare IDEA application 


\subsection{Standardization of operations}

IDEA software can deliver much higher efficiency and productivity by creating and editing the macro-commands with IDEA Script and Visual Script.

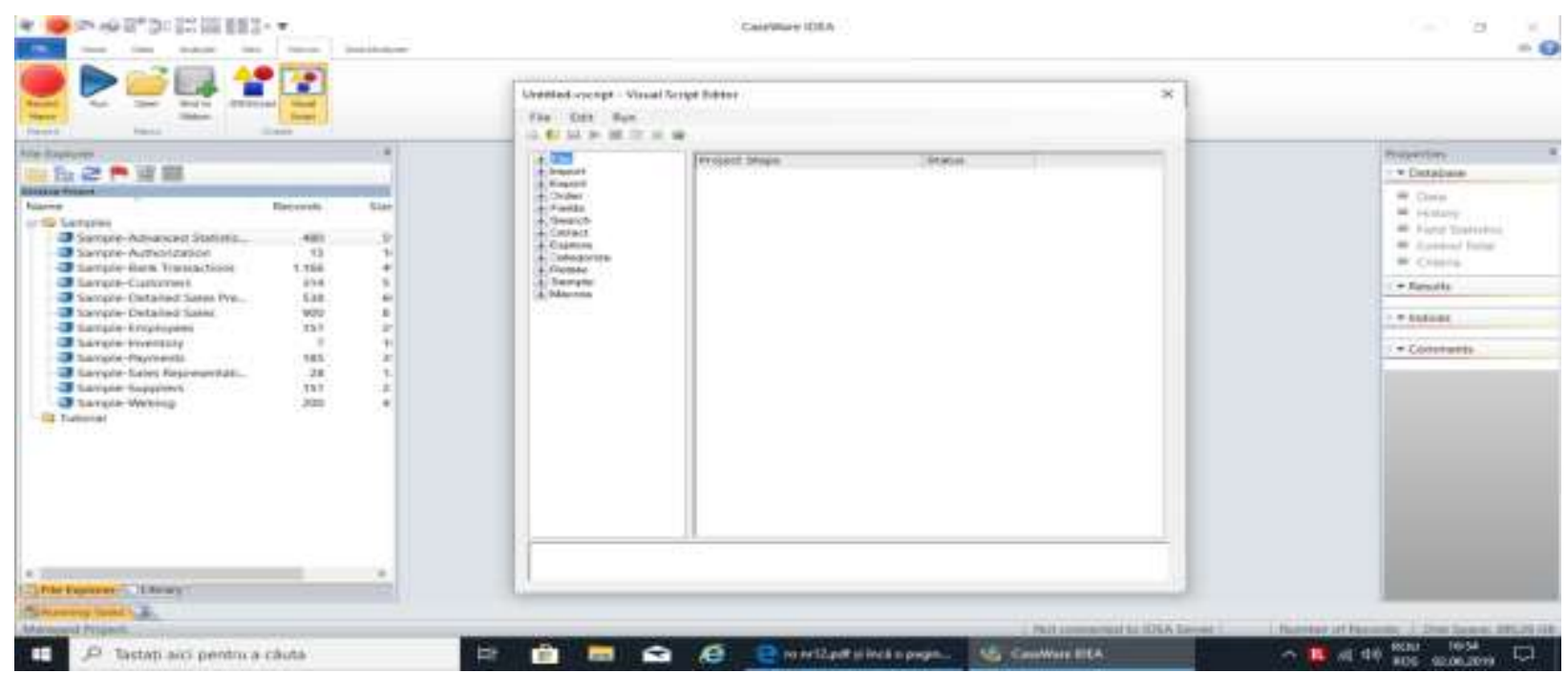

Figure 5. The "Visual Script Editor" used for edit of macro-commands (a collection of recorded commands to be launched in execution in block or whenever is necessary) in IDEA application

Source: Extract from CaseWare IDEA application

\subsection{Review and reporting}

It can be done using reports, graphs, and tables created using the Pivot Table, and data can be played and analyzed in a multidimensional manner.

The steps in the audit activity are automatically documented using Project Overview function. It provides a graphical or table history of auditors' actions on databases, reports that the auditors can export, print or share with management and other stakeholders.

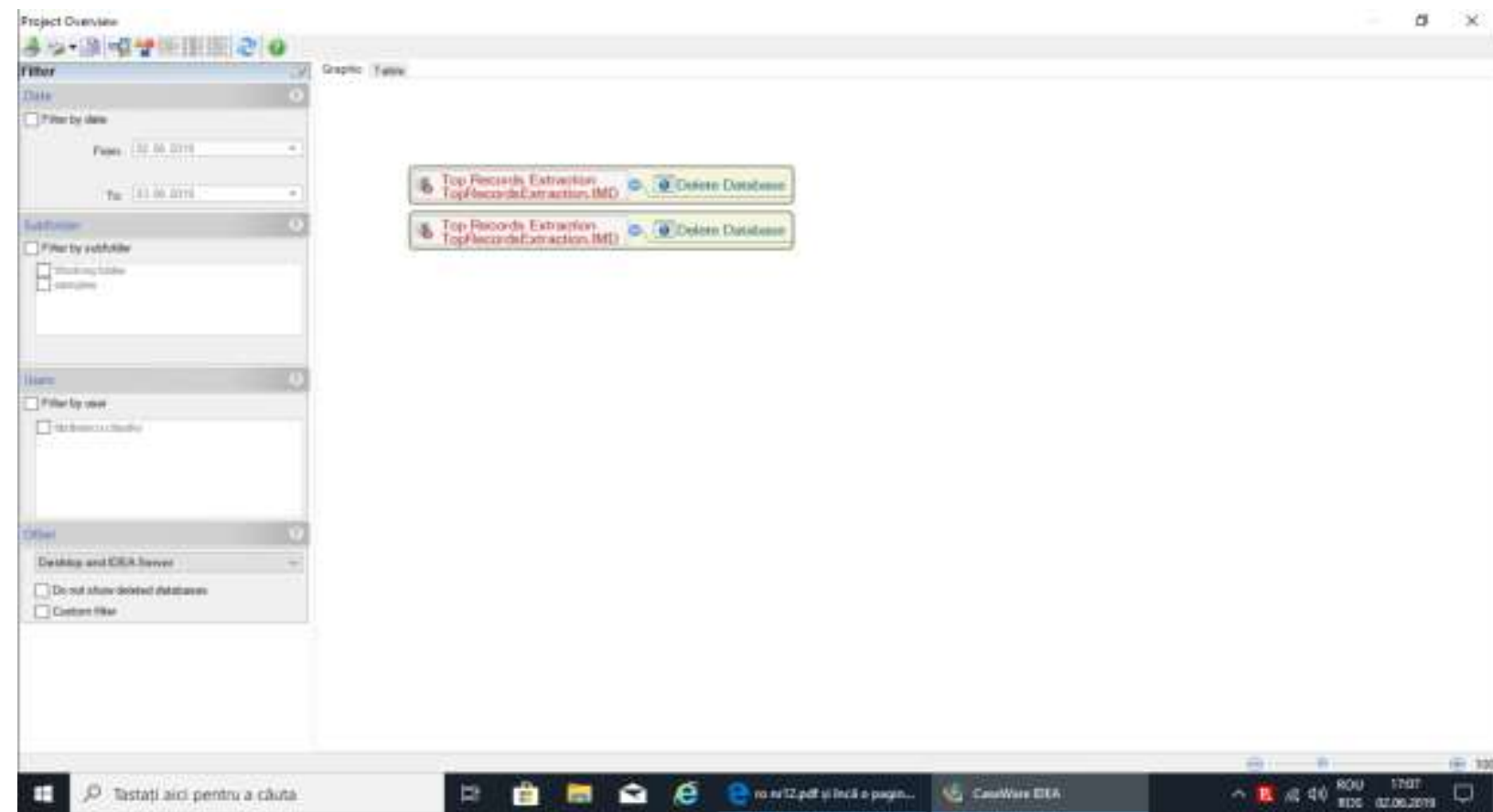

Figure 6. The "Project Overview" Menu in IDEA application, that offers a view on the entire project, from its creation to the end of operations

Source: Extract from CaseWare IDEA application

With a new design versus previous versions, the IDEA Version 9 interface is especially designed for data analysis, being a powerful yet easy-to-use tool built to deliver optimal performance in audit work.

The interface provides remarkable functionality, letting us easily discover over 100 specific audit commands, including features and features that are not found in generic software. 
Performing a complex, analytical and detailed analysis is of no use to auditors if they cannot communicate its results. IDEA facilitates data sharing and requires great interoperability with a variety of export files including Microsoft Access, XML, Text, RTF (Microsoft Word), PDF, and Microsoft Excel.

\section{Conclusions and recommendations}

The main conclusions drawn from the use of CaseWare IDEA at the level of the Chamber of Accounts in Galati in 2017 were:

* the application was used in 6 control / audit actions out of a total of 48 shares (12.5\%);

* no external public auditor participated in the training program on the use of IDEA in that year;

* of the total value of the deficiencies found in the control / audit actions used by IDEA, 47.98\% of them represent deviations clearly identified with the respective application, of which: for additional income $=$ $24,45 \%$, for damages $=6,24 \%$ and for other financial-accounting irregularities $=77,86 \%$, respectively;

* as compared to previous years there is a stagnation of the number of external public auditors using the IDEA application, as well as fluctuations (increases / decreases), but with an increasing trend, of the value of the results obtained by using the respective software.

As suggestions for improvement of the activity we can mention:

* encouraging the participation of many external public auditors in professional training courses in the field of using the IDEA information application, organized by the Chambers of Accounts by their own trainer;

* informing the external public auditors about the results obtained through the IDEA information application in the control / audit activity, of the central and territorial structures of the Romanian Court of Accounts;

* preparing the Chambers of Accounts staff for the use of IT applications at verified public entities level (for example - software for tax and local tax management, financial accounting, payroll, agricultural register, etc.), in particular with respect to the reports that these applications generate;

* the initiation of own trainers at the level of each Chamber of Territorial Accounts and the Romanian Court of Accounts.

In conclusion, we proposed to disseminate the findings made with the CaseWare IDEA computer application to external public auditors who do not use it and we hope that the auditors will increase the degree of training in using this software product.

\section{References}

1. Brezeanu P. (coord.) - Audit financiar: repere metodologice, etice și istorice, reglementări internaţionale (ISA) extrase, Editura Cavallioti, București, 2008

2. CaseWare IDEA, site https://idea.caseware.com/

3. CaseWare IDEA, site https://idea.caseware.com/category/content-type

4. Documents used in the activity of Romanian Court of Accounts

5. Ghiţă M., Sprânceană M. - Auditul intern al instituţiilor publice, Editura Tribuna Economică, București, 2004

6. Law no. 94/1992 on the organization and functioning of the Romanian Court of Accounts

7. The regulation regarding the organization and development of the specific activities of the Court of Accounts, as well as the valorization of the documents resulting from these activities, approved by the Decision of the Plenary of the Court of Accounts no. 155 / 29.05.2014 